\title{
Inadvertent internal carotid artery (ICA) injury during transsphenoidal surgery: review of literature
}

\author{
Hieder Al-Shami ${ }^{1 *}$ (D) and Ahmad K. Alnemare ${ }^{2}$
}

\begin{abstract}
Background: Internal carotid artery (ICA) injury is a hazardous catastrophe for the skull base surgery team. We aimed to illustrate the vital joints in this hazardous event during endoscopic surgery.

Main text: The condition is rare (1.1\%) but fatal per se. Working in the field of endoscopic surgery is not free of charges. It demands a thorough knowledge of anatomy, variations, and pathoanatomy to expect what can be seen thereafter. Once the injury occurs, one must have a quite clear plan to proceed. Marvelous bleeding is confusing not only in the field but also in the mind process.

Conclusion: Endoscope teams when expose to this event should think in a stepwise manner. In our review, we explained the pathoanatomy of the field after an injury, pre-conditions of injury, and how to avoid certain drawbacks during management.
\end{abstract}

Keywords: ICA, Pituitary surgery, Intraoperative injury, Skull base surgery

\section{Background}

Carotid artery injury (CAI) is regarded as a nightmare for every skull base surgeon during his carrier [1, 2]. This derangement can change the roadmap of a successful surgery into a catastrophe. Endoscopic skull base surgery has been evolved over the last decades and recruited many candidates to its field [3, 4]. However, it requires a long learning curve and a strong anatomical base. The anatomical knowledge in endoscopic skull base surgery is not confined to typical parameters and fixed points. In contrast, strong skull base knowledge is embedded in the exact identification of variations, anomalies and pathoanatomical changes that exerted by the diverse pathologies [5]. These "obstacles" were prophylactically prohibited by advanced neuroimaging modalities.

Although, carotid artery injury is still possible whatever the complexity of lesion and the experience of the surgeon [6]. The insult of the carotid artery (as any other hemorrhage) is immediate, unlike cerebrospinal fluid (CSF) leakage which can be delayed and under low pressure. Other insults that can happen to the carotid artery are vessel spasm, thrombosis, pseudoaneurysm formation, and finally carotid-cavernous fistula $[7,8]$.

The incidence of carotid artery injury in transsphenoidal surgery is $1.1 \%[1,2,6]$. It has been recorded previously in different situations like sinus surgery [9] and during treatment of giant cell tumors of clival regions [10]. It is higher in extended lesions like chordomas and expanded endonasal endoscopic surgeries and reach up to $9 \%[2]$.

In the works of literature, no standard protocols have existed for management $[6-8,11-13]$. We shall represent our review of the current management ideas previously reported.

\footnotetext{
* Correspondence: Adamhouse73@gmail.com

${ }^{1}$ Al-Ahly Bank Hospital, Al-Amal Hospital, Cairo, Egypt

Full list of author information is available at the end of the article
}

\section{Springer Open}

(- The Author(s). 2021 Open Access This article is licensed under a Creative Commons Attribution 4.0 International License, which permits use, sharing, adaptation, distribution and reproduction in any medium or format, as long as you give appropriate credit to the original author(s) and the source, provide a link to the Creative Commons licence, and indicate if changes were made. The images or other third party material in this article are included in the article's Creative Commons licence, unless indicated otherwise in a credit line to the material. If material is not included in the article's Creative Commons licence and your intended use is not permitted by statutory regulation or exceeds the permitted use, you will need to obtain permission directly from the copyright holder. To view a copy of this licence, visit http://creativecommons.org/licenses/by/4.0/. 


\section{Main text}

\section{Systematic reviews}

During the past 5 years, two systematic reviews discussing the reported incidence of ICA injury in endoscopic endonasal surgery were conducted. The first one was held by Chin and colleague (2016) [8]. They reviewed 25 articles with 50 cases in different endoscopic purposes and not exclusively discussing pituitary surgery. They found that the most commonly injured ICA segment was the cavernous (34 cases), followed by the ophthalmic (three cases). Injuries occurred more commonly on the left than right and throughout all steps of expanded endonasal sphenoidal surgery (EESS). The second review was conducted by Perry and colleagues (2019) [14]. They estimated the incidence of ICA injury in different approaches of transsphenoidal pituitary surgery (microscopic versus endoscopic) exclusively. They reported 35 cases/11149 patients $(5 / 2672(0.2 \%)$ versus $30 / 8477$ $(0.4 \%))$ for microscopic and endoscopic transsphenoidal surgery respectively.

\section{Preoperative measures}

Skull base surgery has long-run evolution from the first elementary steps of sinus surgery up to extended skull base surgery [13]. The whole skeleton of endoscopic surgery is made up of anatomy [5]. Solid knowledge is a good shield against carotid artery injury. Kassam and coworkers developed a special classification system to minimize neurovascular complications and enhance anatomical knowledge [15]. Prophylactic identification of injury susceptibility always wins. Valentine and Wormald published their article that identified the risk factors for carotid artery injury and failure to obtain visualization of carotid was one of these factors [16]. In 2016, Valentine and co-workers reproduced the scenario of carotid injury in sheep and they applied effective training strategies to control bleeding [17].

\section{Anatomy factor}

The relationship between the artery and sphenoid sinus is not anatomically fixed [5]. The internal carotid artery (ICA) is shielded with a very thin layer of bone $(0.5 \mathrm{~mm})$ thick and is not sufficient to protect the artery from trivial manipulation around it [18]. It has been found that up to $4 \%$ of cases, the internal carotid artery is separated from sinus but a mucosal membrane and dura [18]. Fernandez-Miranda and colleagues studied the anatomic relationships of sphenoid septa and ICA anatomically, they found that most (87\%) of the intrasphenoidal septations insert at the carotid artery in the parasellar or paraclival segments [19]. When more than one septation is present, at least one of them will insert into the carotid prominence [20, 21]. Previous studies, however, have shown varying results. Abdullah et al. [22] examined by computed tomography (CT) with 5-mm slice thickness of 70 studies, however, have shown varying results. Abdullah et al. found that in only 22 of 70 subjects (31\%), the septa were related to the internal carotid artery. Unal and colleagues studied the anatomic variations in the sphenoidal septa were related to the internal carotid artery [23]. They studied the anatomic variations in the sphenoid sinus of 56 subjects through 3-mm slice thickness CTs and showed that in 34 of 112 sides $(30.3 \%)$, a septum protruded the ICA. However, in Fernandez-Miranda et al. study, the CT slice thickness was only $1 \mathrm{~mm}$. Rhoton examined sphenoidal septa and found they are terminating into the carotid artery in $40 \%$ of specimens [24]. He also examined 50 adult sphenoid sinuses and recorded about 30\% incidence of septa inserting into the carotid prominence.

However, all approaches in transsphenoidal surgery are directed to the midline. The distance between the two arteries is ranging from 8 to $10 \mathrm{~mm}$. So, tracking the midline is not always a working step; for example, multiple septations of the sphenoid sinus may include septal walls inserted into the ICA bony canal [25]. Cavernous ICA anomalies are rare in the general population [26] and merely recorded in patients with pituitary pathology. Few reports on concurrent association with cavernous ICA aneurysms which result in ICA rupture [27-29].

\section{Patient factor}

Several factors were associated with cavernous ICA injury. These factors included revision surgery, radiotherapy, large clival mass, acromegalic features, and bromocriptine therapy for a long time $[4,8,9]$.

\section{Tumor factor}

High-definition, multi-slice CT scan of paranasal sinuses should be available to the pituitary surgery team before the induction of general anesthesia [13]. Computed tomography is important to delineate the bony skeleton of the surgical corridor while magnetic resonance (MR) angiography shows the vascular tree around the pituitary tumors. Recent studies recommended the utilization of intraoperative neuro-navigation to avoid vascular injury [6, 30].

Tumors come in contact with ICA are mainly encasing tumors other than destructive in nature. This encasement weakens the artery wall from without and makes it susceptible to bleed and vasospasm [31]. Vasospasm can result from tumor dissection over a vessel or cavernous sinus hemostasis by inserting multiple layers of surgifoam [16].

\section{Intraoperative measures}

The ICA injury harbor high pressure and flow stream of blood that can disturb the scene immediately. It is important to control the field immediately to apply a quiet 
environment able to set strategies to deal with this catastrophe [32].

\section{Surgical field control}

From the literature review, certain points are important to be achieved. These points are the following:

- Blunt instruments like a blunt suction tube, curettes, and dissectors are advocated by the authors [33].

- Bone chips should be removed better by serial cutting with low profile Kerrison other than twisting and grasping. Besides, using diamond burrs are preferred than cutting burrs [34].

- The endoscopic surgery team is usually composed of neurosurgeons and ENT specialists. Usually, the operative steps before durotomy are held by ENT (ear, nose, and throat) surgeons. At the event, two surgeons should be involved. One should direct the bloodstream away from the camera while the other tries to get visualization to achieve hemostasis [2].

- Large bore suction tubes (two 8-10F) should be introduced in the field. The suction tubes should be applied at the inferior angle of the field to direct blood away from the endoscope $[2,10]$.

- A pedicled septal flap should be prepared at once and applied gently to the nasopharynx [35].

- The second surgeon must put the suction tip to the puncture site [1].

\section{Hemostasis}

Many methods were tried to save the catastrophic situation and ICA ligation was one of them. Carotid artery ligation is not a wise decision as to its principle [7, 36, 37]. Generally, in endoscopic pituitary surgery, the dominance of ICA is not in question. Hence, ligation can lead to remarkable stroke and death. Besides, endovascular treatment will be omitted as an option. The mainstay of treatment is nasal packing $[4,7,33]$. Nasal packing is not advocated if the dura is opened if so, shift to other strategies [1].

Sphenoid ostium should be widened sufficiently to nasal packing. Carotid artery compression is advocated ipsilaterally. Weidenbecher and coworkers advised compressing both carotids [38]. Head elevation and controlled hypotension are not scientific strategies to stop bleeding [6, 7]. In contrast, normotensive is advised to preserve cerebral perfusion pressure. There are many options for nasal packing in the market, gauze still the easiest, most available, and sufficient to do the required compression [16]. On the contrary, nasal packing has its own complications. Overpacking and infection are the main complications of nasal packing [39]. Overpacking exerts enormous pressure on the carotid artery that leads to ischemia thereafter $[34,39]$.

\section{Muscle patch}

Muscle patch achieved hemostasis in animal models of ICA injury [34, 39]. Muscle patch contains specific materials that enhance hemostasis better than cellulose and thrombin-gelatin matrix [3, 8]. A pseudoaneurysm can be developed even in the presence of a muscle patch. Muscle patch is prepared from quadriceps, fascia lata, and sternocleidomastoid muscle. The muscle patch is harvested and crushed by metal surfaces to maintain its delicate or sheet-like appearance [39]. The graft is then introduced by using Blakesley forceps with tight adherence to the injury site [1]. The graft needs $10-15 \mathrm{~min}$ to maintain hemostasis. Septal flap might be applied then over the muscle graft when the carotid artery needed to be dissected thereafter. Fibrin glue might also be used over the muscle patch $[16,38]$.

\section{Closure of injured vessel}

There is a delicate line between having good hemostasis by closing the defect and achieving no stenosis [32]. Laws and colleagues described a method of carotid artery repair by suturing $[40,41]$. Other experimental studies reformed a special clip for ICA injury. A specialized U-clip device to close the rupture site by using vascular clamp [16, 34, 40, 42]. This method was found to be very effective when exposure around the artery is sufficient. Unfortunately, this type of clips is no longer available from the manufacturers.

Aneurysm clip (T2) was capable of achieving hemostasis in all injury types as studied by Padhye and co-workers [34].

Bipolar electrocauterization is not an effective model of treatment even in animal studies. Cauterization produced a coagulum at the site of injury; this coagulum makes the wall vulnerable to further bleeding, enlarging the defect and stenosis [34].

\section{Endovascular treatment}

Vessel occlusion and decreased arterial flow are both can be achieved by endovascular treatment [2]. In many scenarios, the endoscopic achievement of hemostasis is before transfer to an angiography suite. Endovascular occlusion of the vessel is done usually by coil or balloon [43]. Either method used, the coil should be deployed at the site of injury to prevent extravasation of blood through a defect in an anterograde or retrograde direction [27]. Therefore, care should be paid to avoid ophthalmic artery occlusion. If time permits, collateral circulation should be studied well as well as the feasibility to occlude the offending vessel (Wada test) [7, 44]. The stent graft is now performed by many interventionists. This technique is a challenging process but still effective in achieving vessel patency. Spasm of ICA, distant migration, and stenosis are possible 
complications [27, 43]. Sylvester and colleagues [43] suggested an algorithm for treatment of ICA injury by implementation of several endovascular methods, and high flow external carotid-to-internal carotid (EC-IC) bypass was the final choice when all methods failed.

\section{Postoperative measures}

Pseudoaneurysm and carotid-cavernous fistula are both hazardous and late complications to ICA injury [45]. Pseudoaneurysms are as high as $60 \%$ after ICA injury; there is a risk of rupture for up to 3 months [7]. Angiographic repair by grafting of occluding is the most powerful preventive measure ever estimated. Similarly, carotid-cavernous fistula can be treated in the same way as well [7].

\section{Conclusion}

Endoscope teams when expose to this event should think in a stepwise manner. In our review, we explained the pathoanatomy of the field after an injury, preconditions of injury, and how to avoid certain drawbacks during management.

\section{Abbreviations}

CAl: Carotid artery injury; CSF: Cerebrospinal fluid; CT: Computed tomography; EC-IC: External carotid-Internal carotid; ENT: Ear, nose, and throat specialty; EESS: Expanded endonasal sphenoidal surgery; ICA: Internal carotid artery; MR: Magnetic resonance

\section{Acknowledgements}

Many thanks to our neurosurgery team for their support, knowledge, and empowering our skills especially in the precious field of skull base surgery.

\section{Authors' contributions}

HA is responsible for collecting data, skeletonizing the manuscript, writing of the manuscript, and revision as well. AN provided language editing, citing additional references, manuscript revision, and proofreading. All authors have read and approved the final manuscript.

\section{Funding}

The authors funded this work.

\section{Availability of data and materials}

All the data retrieved in this article are already published previously and available at ease.

\section{Declarations}

Ethics approval and consent to participate

Not applicable

\section{Consent for publication}

Not applicable.

\section{Competing interests}

The authors declare that they have no competing interests.

\section{Author details}

${ }^{1}$ Al-Ahly Bank Hospital, Al-Amal Hospital, Cairo, Egypt. ${ }^{2}$ Otolaryngology Department, College of Medicine, Majmaah University, Al-Majmaah 11952, Saudi Arabia.
Received: 24 February 2020 Accepted: 15 April 2021

Published online: 10 May 2021

\section{References}

1. AlQahtani AA, Castelnuovo P, Nicolai P, Prevedello DM, Locatelli D, Carrau RL. Injury of the internal carotid artery during endoscopic skull base surgery: Prevention and management protocol. Otolaryngologic Clinics of North America. 2016;49(1):237-52. https://doi.org/10.1016/j.otc.2015.09.009.

2. Padhye $\mathrm{V}$, Valentine $\mathrm{R}$, Wormald P-J. Management of carotid artery injury in endonasal surgery. Int Arch Otorhinolaryngol. 2014;18(S 02):S173-8.

3. Duek I, Sviri GE. Endoscopic repair of carotid artery injury. Otolaryngol. 2015; 05(06):5-7.

4. Duek I, Sviri G, Amit M, Gil Z. Endoscopic endonasal repair of internal carotid artery injury during endoscopic endonasal surgery. J Neurol Surg Rep. 2017;78(04):e125-8.

5. Abuzayed B, Tanriover N, Gazioglu N, Sanus GZ, Ozlen F, Biceroglu H, et al. Endoscopic endonasal anatomy and approaches to the anterior skull base. $J$ Craniofacial Surg. 2010;21(2):529-37.

6. Rareş $C$, Moncef $B$, Timothée J, Gerard R, Emmanuel J. Tips and tricks to manage vascular risks using the transnasal endoscopic approach to pituitary adenomas. Acta Medica Marisiensis. 2015;61(4):349-55. https://doi.org/10.1 515/amma-2015-0100

7. Lum SG, Gendeh BS, Husain S, Gendeh HS, Ismail MR, Toh CJ, et al. Internal carotid artery injury during endonasal sinus surgery: Our experience and review of the literature. Acta Otorhinolaryngologica Italica. 2019;39(2):130-6.

8. Chin OY, Ghosh R, Fang CH, Baredes S, Liu JK, Eloy JA. Internal carotid artery injury in endoscopic endonasal surgery: a systematic review. Laryngoscope. 2016;126(3):582-90. https://doi.org/10.1002/lary.25748.

9. lacoangeli M, Di Rienzo A, Re M, Alvaro L, Nocchi N, Gladi M, et al. Endoscopic endonasal approach for the treatment of a large clival giant cell tumor complicated by an intraoperative internal carotid artery rupture. Cancer Management Res. 2013;5(1):21-4.

10. Gardner PA, Snyderman CH, Fernandez-Miranda JC, Jankowitz BT. Management of major vascular injury during endoscopic endonasal skull base surgery. Otolaryngologic Clinics of North America. 2016;49(3):819-28. https://doi.org/10.1016/j.otc.2016.03.003.

11. Stankiewicz JA, Park AH, Chow JM. Internal carotid artery injury during sinus surgery: A protocol for management. Operative Techniques in Otolaryngology-Head and Neck Surgery. 2001;12(1):25-7. https://doi.org/1 0.1053/otot.2001.22200.

12. Vaz-Guimaraes F, Gardner PA, Fernandez-Miranda JC, Wang EW, Snyderman $\mathrm{CH}$. Endoscopic endonasal skull base surgery for vascular lesions: A systematic review of the literature. J Neurosurg Sci. 2016;60(4):503-13.

13. Koitschev A, Simon C, Löwenheim H, Naegele T, Ernemann U. Management and outcome after internal carotid artery laceration during surgery of the paranasal sinuses. Acta Oto-Laryngologica. 2006;126(7):730-8. https://doi. org/10.1080/00016480500469578.

14. Perry A, Graffeo CS, Meyer J, Carlstrom LP, Oushy S, Driscoll CLW, et al. Beyond the learning curve: Comparison of microscopic and endoscopic incidences of internal carotid injury in a series of highly experienced operators. World Neurosurg. 2019;131:e128-35. https://doi.org/10.1016/j. wneu.2019.07.074.

15. Kassam AB, Gardner P, Snyderman C, Mintz A, Carrau R. Expanded endonasal approach: fully endoscopic, completely transnasal approach to the middle third of the clivus, petrous bone, middle cranial fossa, and infratemporal fossa. Neurosurgical Focus. 2005 Jul 15;19(1):E6.

16. Valentine R, Wormald PJ. Carotid artery injury after endonasal surgery. Otolaryngologic Clin North Am. 2011;44(5):1059-79. https://doi.org/10.1016/ j.otc.2011.06.009.

17. Valentine R, Padhye V, Wormald PJ. Management of arterial injury during endoscopic sinus and skull base surgery. Current Opinion in Otolaryngology and Head and Neck Surgery. 2016;24(2):170-4. https://doi.org/10.1097/MOO. 0000000000000239

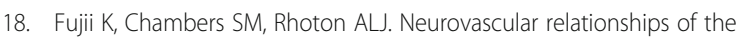
sphenoid sinus. A microsurgical study. J Neurosurg. 1979;50(1):31-9. https:// doi.org/10.3171/jns.1979.50.1.0031.

19. Fernandez-Miranda JC, Prevedello DM, Madhok R, Morera V, Barges-Coll J, Reineman K, et al. Sphenoid septations and their relationship with internal carotid arteries: Anatomical and radiological study. Laryngoscope. 2009; 119(10):1893-6. https://doi.org/10.1002/lary.20623. 
20. Awadalla AM, Hussein Y, Elkammash TH. Anatomical and radiological parameters of the sphenoid sinus among Egyptians and its impact on sellar region surgery diagnostic radiology. Egyptian J Neurosurg. 2015;30(1):1-12.

21. Dal Secchi MM, Dolci RLL, Teixeira R, Lazarini PR. An analysis of anatomic variations of the sphenoid sinus and its relationship to the internal carotid artery. International Archives of Otorhinolaryngology. 2018;22(2):161-6. https://doi.org/10.1055/s-0037-1607336.

22. Abdullah B, Arasaratnam S, Kumar G, Gopala K. The Sphenoid sinuses: Computed tomographic assessment of septation, relationship to the internal carotid arteries, and sidewall thickness in the Malaysian population. Hong Kong J Radiol. 2001;4(3):185-8.

23. Unal B, Bademci G, Bilgili YK, Batay F, Avci E. Risky anatomic variations of sphenoid sinus for surgery. Surgical and Radiologic Anatomy. 2006;28(2): 195-201. https://doi.org/10.1007/s00276-005-0073-9.

24. Thapar K, Kovacs K, Scheithauer B, Lloyd RV, Rhoton AL. Anatomy of the pituitary gland and sellar region. In: Thapar K, Kovacs K, Scheithauer BW, Lloyd RV, editors. Diagnosis and management of pituitary tumors. Totowa, NJ: Humana Press; 2003. p. 13-40.

25. Amin SM, Nasr AY, Saleh HA, Foad MM, Herzallah IR. Endoscopic orientation of the parasellar region in sphenoid sinus with ill-defined bony landmarks: an anatomic study. Skull base. 2010:20(6):421-8.

26. Uchino A, Sawada A, Takase Y, Kudo S. MR angiography of anomalous branches of the internal carotid artery. American Journal of Roentgenology. 2003;181(5):1409-14. https://doi.org/10.2214/ajr.181.5.1811409.

27. Park YS, Jung JY, Ahn JY, Kim DJ, Kim SH. Emergency endovascular stent graft and coil placement for internal carotid artery injury during transsphenoidal surgery. Surgical Neurology. 2009;72(6):741-6. https://doi. org/10.1016/j.surneu.2009.05.003.

28. Wijethunga WMUA, Dissanayake HA, Perera S, Katulanda P. Intra cavernous aneurysm of internal carotid artery masquerading as a pituitary adenoma: a case report. BMC Research Notes. 2018;11(1):237. https://doi.org/10.1186/ s13104-018-3329-2.

29. Duarte FHG, Machado MC, de Lima JR, Salgado LR. Severe hyperprolactinemia associated with internal carotid artery aneurysm: differential diagnosis between prolactinoma and hypothalamic-pituitary disconnection. Arquivos Brasileiros de Endocrinologia \& Metabologia. 2008; 52(7):1189-93. https://doi.org/10.1590/S0004-27302008000700017.

30. Rowan NR, Turner MT, Valappil B, Fernandez-Miranda JC, Wang EW, Gardner PA, et al. Injury of the carotid artery during endoscopic endonasal surgery: Surveys of skull base surgeons. J Neurol Surg, Part B: Skull Base. 2018;79(3): 302-8. https://doi.org/10.1055/s-0037-1607314.

31. Sol YL, Lee SK, Choi HS, Lee YH, Kim J, Kim SH. Evaluation of MRI criteria for cavernous sinus invasion in pituitary macroadenoma. J Neuroimaging. 2014; 24(5):498-503. https://doi.org/10.1111/j.1552-6569.2012.00710.x.

32. Valentine $R$, Wormald PJ. Controlling the surgical field during a large endoscopic vascular injury. Laryngoscope. 2011 Mar;121(3):562-6. https:// doi.org/10.1002/lary.21361.

33. Pacca P, Jhawar SS, Seclen DV, Wang E, Snyderman C, Gardner PA, et al. "Live cadaver" Model for internal carotid artery injury simulation in endoscopic endonasal skull base surgery. Operative Neurosurg. 2017;13(6): 732-8. https://doi.org/10.1093/ons/opx035.

34. Padhye V, Valentine R, Paramasivan S, Jardeleza C, Bassiouni A, Vreugde S, et al. Early and late complications of endoscopic hemostatic techniques following different carotid artery injury characteristics. Int Forum Allergy Rhinol. 2014;4(8):651-7. https://doi.org/10.1002/alr.21326.

35. Amin SM, Fawzy TO, Hegazy AA. Composite vascular pedicled middle turbinate flap for reconstruction of sellar defects. Ann Otol, Rhinol Laryngol. 2016;125(9):770-4. https://doi.org/10.1177/0003489416654709.

36. Karadag A, Kinali B, Ugur O, Oran I, Middlebrooks EH, Senoglu M. A case of pseudoaneurysm of the internal carotid artery following endoscopic endonasal pituitary surgery: Endovascular treatment with flow-diverting stent implantation. Acta Medica (Hradec Kralove). 2017;60(2):89-92.

37. Maza G, VanKoevering KK, Yanez-Siller JC, Baglam T, Otto BA, Prevedello DM et al. Surgical simulation of a catastrophic internal carotid artery injury: a laser-sintered model. Int Forum Allergy Rhinol. 2019;9(1):53-9. https://doi. org/10.1002/alr.22178.

38. Weidenbecher $\mathrm{M}$, Huk WJ, Iro H. Internal carotid artery injury during functional endoscopic sinus surgery and its management. Eur Arch OtoRhino-Laryngol. 2005;262(8):640-5. https://doi.org/10.1007/s00405-004-08888
39. Valentine R, Boase S, Jervis-Bardy J, Dones Cabral JD, Robinson S, Wormald PJ. The efficacy of hemostatic techniques in the sheep model of carotid artery injury. Int Forum Allergy Rhinol. 2011;1(2):118-22. https://doi.org/10.1 002/alr.20033.

40. Solares CA, Ong YK, Carrau RL, Fernandez-Miranda J, Prevedello DM,

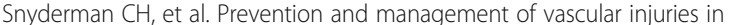
endoscopic surgery of the sinonasal tract and skull base. Otolaryngol Clin North Am. 2010;43(4):817-25. https://doi.org/10.1016/j.otc.2010.04.008.

41. Laws ER. Vascular complications of transsphenoidal surgery. Pituitary. 1999; 2(2):163-70. https://doi.org/10.1023/A:1009951917649.

42. Duek I, Sviri GE, Amit M, Gil Z. Endoscopic repair of carotid artery injury. Otolaryngology. 2015;05(06):5-7.

43. Sylvester PT, Moran CJ, Derdeyn CP, Cross DT, Dacey RG, Zipfel GJ, et al Endovascular management of internal carotid artery injuries secondary to endonasal surgery: case series and review of the literature. J Neurosurg. 2016;125(5):1256-76. https://doi.org/10.3171/2015.6.JNS142483.

44. Zhang Y, Tian Z, Li C, Liu J, Zhang Y, Yang X, et al. A modified endovascular treatment protocol for iatrogenic internal carotid artery injuries following endoscopic endonasal surgery. J Neurosurg. 2020;132(2):343-50. https://doi. org/10.3171/2018.8.JNS181048.

45. Rodrigues JS, Gupta A, Parakh A. Pseudoaneurysm of internal carotid artery following endoscopic endonasal pituitary surgery requiring endovascular treatment in an acromegalic patient with a difficult airway. J Neuroanaesthesiol Critical Care. 2020;7(01):34-7.

\section{Publisher's Note}

Springer Nature remains neutral with regard to jurisdictional claims in published maps and institutional affiliations.

\section{Submit your manuscript to a SpringerOpen ${ }^{\circ}$ journal and benefit from:}

- Convenient online submission

- Rigorous peer review

- Open access: articles freely available online

High visibility within the field

- Retaining the copyright to your article

Submit your next manuscript at $\boldsymbol{\nabla}$ springeropen.com 